\title{
Effectiveness of Medications Used to Attenuate Antipsychotic-Related Weight Gain and Metabolic Abnormalities: A Systematic Review and Meta-Analysis
}

\author{
Lawrence Maayan ${ }^{1,2}$, Julia Vakhrusheva ${ }^{2}$ and Christoph $U$ Correll*,3,4,5 \\ 'Child Study Center, New York University School of Medicine, New York, NY, USA; ${ }^{2}$ Nathan Kline Institute for Psychiatric Research, Orangeburg, \\ NY, USA; ${ }^{3}$ The Zucker Hillside Hospital, Psychiatry Research, North Shore-Long Island Jewish Health System, Glen Oaks, NY, USA; ${ }^{4}$ Albert \\ Einstein College of Medicine, Bronx, NY, USA; ${ }^{5}$ The Feinstein Institute for Medical Research, Manhasset, NY, USA
}

\begin{abstract}
Antipsychotic-related weight gain and metabolic effects are a critical outcome for patients requiring these medications. A literature search using MEDLINE, Web of Science, PsycNET, and EMBASE for randomized, open and double-blind, placebo-controlled trials of medications targeting antipsychotic-induced weight gain was performed. Primary outcome measures were change and endpoint values in body weight and body mass index (BMI). Secondary outcomes included $\geqslant 7 \%$ weight gain, all-cause discontinuation, change in waist circumference, glucose and lipid metabolism parameters, and psychiatric symptoms. Sensitivity analyses were conducted to explain heterogeneity of the results. Across 32 studies including 1482 subjects, 15 different medications were tested: amantadine, dextroamphetamine, d-fenfluramine, famotidine, fluoxetine, fluvoxamine, metformin, nizatidine, orlistat, phenylpropanolamine, reboxetine, rosiglitazone, sibutramine, topiramate, and metformin + sibutramine. Compared with placebo, metformin had the greatest weight loss $(N=7, n=334,-2.94 \mathrm{~kg}$ (confidence interval (Cl:-4.89,-0.99)), followed by d-fenfluramine $(N=1, n=16,-2.60 \mathrm{~kg}$ (Cl:-5.14,-0.06)), sibutramine $(N=2, n=55,-2.56 \mathrm{~kg}(\mathrm{Cl}:-3.91,-1.22))$, topiramate $(\mathrm{N}=2, n=133,-2.52 \mathrm{~kg}(\mathrm{Cl}:-4.87,-0.16))$, and reboxetine $(\mathrm{N}=2, n=79,-1.90 \mathrm{~kg}(\mathrm{Cl}:-3.07,-0.72))$. Weight loss remained significant with metformin initiation after weight gain had occurred, but not when started concomitantly with antipsychotics. Nausea rates were not higher with any treatment compared with placebo. In all, 5 of 15 psychopharmacologic interventions aimed at ameliorating antipsychotic-induced weight gain outperformed placebo. Results were most robust for metformin, although these were modest and heterogeneous. Only one (negative) combination treatment study was available and head-to-head studies are absent. None of the agents were able to entirely reverse weight gain because of antipsychotics. At present, no treatment has sufficient evidence to recommend broad clinical usage. Antipsychotics with no or minimal cardiometabolic liability, as well as interventions that prevent or normalize adverse antipsychotic cardiometabolic effects are needed. Neuropsychopharmacology (2010) 35, 1520-1530; doi:I0.1038/npp.2010.21; published online 24 March 2010
\end{abstract}

Keywords: antipsychotics; weight gain; intervention; pharmacologic; weight loss; metformin

\section{INTRODUCTION}

With the prevailing use of second-generation antipsychotics (SGAs) over first-generation antipsychotics (FGAs) for various severe psychiatric disorders, the adverse effect concern has shifted from extrapyramidal side effects to weight gain and metabolic abnormalities. The reason for this is twofold. First, in spite of the heterogeneity within antipsychotic class, SGAs have a greater risk for weight gain and metabolic adverse effects (Allison et al, 1999; Leucht et al, 2009a; Newcomer, 2005). Second, in addition to adversely affecting quality of life and medication adherence

*Correspondence: Dr CU Correll, Psychiatry Research, The Zucker Hillside Hospital, 75-59 263rd Street, Glen Oaks, NY, I I004, USA, Tel: + 718470 48I2, Fax: + 7I8 343 1659, E-mail: ccorrell@lij.edu Received 24 November 2009; revised 22 January 2010; accepted 3 February 2010
(Allison et al, 2003; Perkins, 2002) weight gain and metabolic abnormalities are reliable risk factors for premature cardiovascular morbidity and mortality (Colton and Manderscheid, 2006; Newcomer, 2005), outcomes that occur at higher rates in the severely mentally ill and are related to antipsychotic treatment (Correll, 2007).

Research into underlying mechanisms has identified some risk factors such as $\mathrm{H} 1$ receptor affinity (Kroeze et al, 2003) and 5HT2c polymorphisms (Templeman et al, 2005). However, the pharmacology of antipsychotic-induced weight gain is largely not understood and very likely multifactorial because of the importance of maintaining energy homeostasis, making the development of targeted pharmacological interventions difficult (Correll and Malhotra, 2004). Consequently, interventions to minimize antipsychotic weight gain have, for the most part, been based on anecdotal, indirect, or theoretical considerations. Besides using lower risk medications first in the treatment 
algorithm, non-pharmacologic and pharmacologic augmentation strategies have been tested. A meta-analysis of 10 behavioral intervention studies $(n=482)$ showed that nutritional counseling was as effective as cognitive behavioral therapy, and that both were superior to treatment as usual without concomitant behavioral intervention in reducing antipsychotic-induced weight gain (Alvarez-Jimenez et al, 2008). Another meta-analysis of 23 trials compared behavioral $(N=5, n=233)$ and pharmacologic interventions $(N=18$, $n=547$ ) with treatment as usual, and concluded that the evidence for pharmacologic weight loss agents was insufficient (Faulkner et al, 2007a). The latest review of 25 pharmacologic weight loss intervention studies $(n=1221)$ concluded that results were promising for amantadine, metformin, reboxetine, sibutramine, and topiramate (Baptista et al, 2008a). Although this work benefitted from additional studies, the investigators did not perform a meta-analysis of the placebo-controlled trials, so that the effects of specific medications relative to each other were not compared. However, such a meta-analytic comparison of individual agents compared to placebo is needed because the lack of head-to-head studies directly comparing different interventions and because the limited number and sample size of randomized trials investigating different agents has made it difficult to evaluate the effectiveness of individual studies and agents. Moreover, data on metabolic effects have been insufficient.

Given the limited database and recent completion of several placebo-controlled studies, we conducted a systematic review and meta-analysis of pharmacologic treatments for the amelioration of antipsychotic-associated weight gain and metabolic abnormalities. We aimed to inform clinical practice by identifying the most promising pharmacologic augmentation strategies while also investigating effects on psychopathology and examining potential moderator variables.

\section{MATERIALS AND METHODS}

\section{Search}

A literature search was performed to find randomized, placebo-controlled trials, both double-blind and open label, using the following electronic databases: MEDLINE, Web of Science, PsycNET, and EMBASE. Search terms included previously studied weight reduction medications: stimulants, H2 blockers, antidepressants, amantadine, dextroamphetamine, d-fenfluramine, famotidine, fluoxetine, fluvoxamine, metformin, nizatidine, orlistat, phenylpropanolamine, reboxetine, rosiglitazone, sibutramine, and topiramate. In addition, the following search terms were used: 'randomized', 'intervention', 'reduction', 'weight', 'weight gain', and 'antipsychotic'. Reference lists of included and relevant studies and reviews were searched for additional studies. When required data were missing, first/corresponding authors were contacted for additional information.

\section{Data Extraction and Outcomes}

All data were extracted by one of the reviewers (LM, JV, CUC) and checked by a second reviewer. Inconsistencies were reviewed and resolved.

\section{Calculations and Analyses}

Data were analyzed using Review Manager 5.0. (RevMan 5.0.18 (PC version), Cochrane Collaboration, Oxford, UK). When calculating continuous outcomes, the inverse variance statistical method and random effects model was used to compensate study heterogeneity. As each study used the same outcome for the studied adverse effects, the weighted mean difference (WMD) with 95\% confidence intervals (CIs) was applied. To analyze effects on psychiatric symptoms that were measured with different scales, standardized mean difference (SMD) was used. For dichotomous outcomes, the Mantel-Hansel statistical method and random effects model were used. When SDs were missing, they were derived from other available statistics or the average SD of other studies with that same medication was used (Leucht et al, 2009b). Number-needed-to-treat (NNT) was derived by calculating the reciprocal of the difference in incidence rates between control and treatment groups (ie, dividing 1 by the difference). Study heterogeneity was measured using the $\chi^{2}$ and I-squared statistics, with $\chi^{2}$ $p<0.05$ and $I$-squared $>50 \%$ indicating heterogeneity (Higgins et al, 2003). In cases of $I$-squared $>50 \%$, sensitivity analyses were conducted to seek reasons for the heterogeneity. The main outcome variables were the effect of individual weight loss agents on (a) body weight and (b) body mass index (BMI). Secondary outcomes included waist circumference, $\geqslant 7 \%$ weight gain, changes in glucose, insulin, leptin, triglycerides, total cholesterol, HDL-cholesterol, LDL-cholesterol, psychiatric symptoms, and all-cause discontinuation.

One study, each, investigating nizatidine (Cavazzoni et al, 2003) and investigating topiramate (Ko et al, 2005) compared two different doses of the respective pharmacologic intervention with placebo. As a result, the placebo group was included twice in the analyses to examine a potential dose response relationship. Thus, the total number of study arms $(N=32+2=34)$ and patients $(n=1482+$ $82=1564)$ in the analyses is higher than the total number of studies $(N=32)$ and patients $(n=1482)$. To examine potential moderator variables, four sensitivity analyses were performed: (1) intervention studies $(N=22, n=947)$ (Arman et al, 2008; Assuncao et al, 2006; Atmaca et al, 2003, 2004; Baptista et al, 2007, 2008b, 2009; Borovicka et al, 2002; Bustillo et al, 2003; Carrizo et al, 2009; Deberdt et al, 2005; Goodall et al, 1988; Graham et al, 2005; Henderson et al, 2005, 2007, 2009; Joffe et al, 2008; Klein et al, 2006; Ko et al, 2005; Modell and Hussar, 1965; Nickel et al, 2005; Wu et al, 2008b), that is, weight loss agent given after weight gain with antipsychotic treatment, $v s$ prevention studies $(N=10, n=535) \quad$ (Baptista et al, 2006; Cavazzoni et al, 2003; Hinze-Selch et al, 2000; Kim et al, 2006; Lu et al, 2004; Poyurovsky et al, 2002, 2003, 2004, 2007; Wu et al, 2008a), that is, weight loss agent was given concomitantly with newly initiated antipsychotic treatment; (2) short-term trials of $\leqslant 8$ weeks $(N=10, n=296)$ (Atmaca et al, 2003, 2004; Henderson et al, 2009; Hinze-Selch et al, 2000; Modell and Hussar, 1965; Nickel et al, 2005; Poyurovsky et al, 2002, 2003, 2004, 2007) vs medium-term trials of $12-16$ weeks $(N=22, n=1186)$ (Arman et al, 2008; Assuncao et al, 2006; Baptista et al, 2006, 2007, 2008b, 2009; Borovicka et al, 2002; Bustillo et al, 2003; Carrizo et al, 2009; 
Cavazzoni et al, 2003; Deberdt et al, 2005; Goodall et al, 1988; Graham et al, 2005; Henderson et al, 2005, 2007; Joffe et al, 2008; Kim et al, 2006; Klein et al, 2006; Ko et al, 2005; Lu et al, 2004; Wu et al, 2008a,b); (3) outpatient status $(N=12, n=454)$ (Assuncao et al, 2006; Borovicka et al, 2002; Bustillo et al, 2003; Carrizo et al, 2009; Goodall et al, 1988; Graham et al, 2005; Henderson et al, 2005, 2007, 2009; Kim et al, 2006; Nickel et al, 2005; Wu et al, 2008b) vs inpatient status $(N=14, n=514)$ (Arman et al, 2008; Baptista et al, 2006, 2008b, 2009; Hinze-Selch et al, 2000; Klein et al, 2006; Ko et al, 2005; Lu et al, 2004; Modell and Hussar, 1965; Poyurovsky et al, 2002, 2003, 2004, 2007; Wu et al, 2008a) vs mixed status $(N=6, n=514)$ (Atmaca et al, 2003, 2004; Baptista et al, 2007; Cavazzoni et al, 2003; Deberdt et al, 2005; Joffe et al, 2008); and (4) adults with chronic antipsychotic treatment $(N=23, n=1149)$ (Assuncao et al, 2006; Atmaca et al, 2003, 2004; Baptista et al, 2006, 2007, 2008b, 2009; Borovicka et al, 2002; Carrizo et al, 2009; Cavazzoni et al, 2003; Deberdt et al, 2005; Goodall et al, 1988; Graham et al, 2005; Henderson et al, 2005, 2007, 2009; Hinze-Selch et al, 2000; Joffe et al, 2008; Kim et al, 2006; Ko et al, 2005; Lu et al, 2004; Modell and Hussar, 1965; Nickel et $a l, 2005)$ vs first episode or youth samples $(N=9$, $n=333$ ) (Arman et al, 2008; Bustillo et al, 2003; Klein et al, 2006; Poyurovsky et al, 2002, 2003, 2004, 2007; Wu et al, 2008a,b).

\section{RESULTS}

Of 1643 abstracts, 45 full texts were inspected, excluding 13 studies (Figure 1). All 32 studies $(n=1482)$ were randomized, placebo-controlled and either double-blind, or openlabel (Supplementary Table 1). Except for two pediatric studies (Arman et al, 2008; Klein et al, 2006), all other trials included adults. Participants' age was 36.3 years in the treatment group and 36.7 years for placebo across 27 adult studies with age data. In two pediatric studies, the age was 12.1 years in the treatment group $(n=34)$ and 11.4 years for placebo $(n=36)$. In total, $55.4 \%$ of participants in the treatment group and $51.9 \%$ in the placebo group were men (23 studies with data). In all, $42.2 \%$ in the treatment group and $50.4 \%$ in the placebo group were Caucasian (nine studies with data). The mean, weighted baseline BMI was 26.9 for the treatment group and 27.1 for the placebo group (26 studies with data). Out of 1482 participants, 1072 (72.3\%) were diagnosed with schizophrenia, schizophreniform, or schizoaffective disorder, 79 (5.3\%) were diagnosed

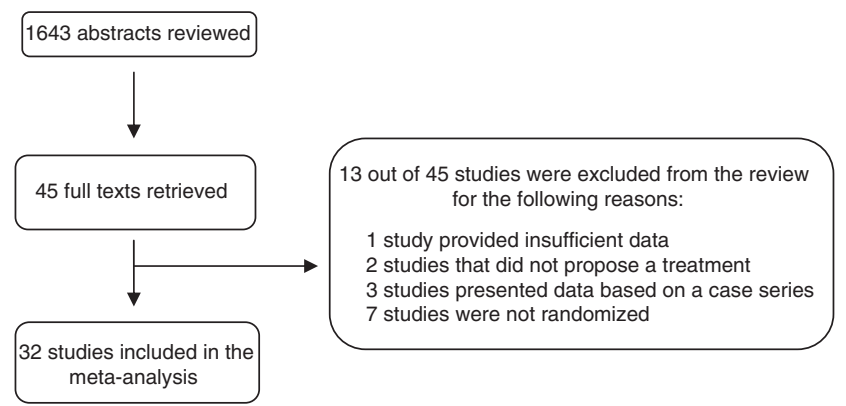

Figure I Flow chart of systematic review. with unipolar or bipolar disorder, $20(1.3 \%)$ were diagnosed with psychosis, and in 311 cases $(21.0 \%$,) the diagnosis was unspecified or specifics were not provided.

Trials lasted 6-16 (mean: 13.1) weeks and included: metformin $(N=7, n=355)$, nizatidine $(N=4, n=292$, one using two different dosages), topiramate $(N=3, n=169$, one using two different dosages), amantadine $(N=2, n=$ 146), fluoxetine $(N=2, n=60)$, fluvoxamine $(N=2, n=$ $91)$, reboxetine $(N=2, n=85)$, sibutramine $(N=2, n=58)$, rosiglitazone $(N=2, n=48)$, dextroamphetamine $(N=1$, $n=20)$, d-fenfluramine $(N=1, n=29)$, famotidine $(N=1$, $n=14)$, orlistat $(N=1, n=71)$, phenylpropanolamine $(N=1, \quad n=16)$, and metformin + sibutramine $(N=1$, $n=28)$. Baseline antipsychotics included olanzapine $(N=18)$, clozapine $(N=6)$, risperidone $(N=2)$, quetiapine $(N=1)$, and mixed SGAs (one trial including clozapine, olanzapine, risperidone, and sulpiride; one trial including clozapine and olanzapine; and one trial including olanzapine, quetiapine, and risperidone). In one older study each, mixed FGAs (fluphenazine, flupenthixol, and clopenthixol) or mixed FGAs with other medications (chlorpromazine, thioridazine, imipramine, and chlordiazepoxide) were the weight-inducing baseline medications for which d-fenfluramine or dextroaphetamine was used, respectively.

All studies provided weight data, with $84.4 \%$ of studies $(N=27)$ providing weight change data and $62.5 \%$ of studies $(N=20)$ reporting endpoint weight. In all, $71.9 \%$ of studies $(N=23)$ provided BMI data, with $46.8 \%(N=15)$ providing BMI change and $50.0 \%(N=16)$ reporting endpoint BMI. Only $25.0 \%$ of studies $(N=8)$ reported waist circumference change, $31.3 \%(N=10)$ reported glucose change or endpoint, $28.1 \%(N=9)$ reported blood lipids change or endpoint, and $18.8 \%(N=6)$ reported insulin or leptin change or endpoint. Only $43.8 \%$ of studies $(N=14)$ provided change or endpoint values in the main psychiatric rating scale (BPRS, PANSS), and 71.9\% $(N=23)$ reported all-cause discontinuation.

\section{Primary Outcomes}

Overall, pharmacologic interventions were associated with a pooled weight change of $-1.99 \mathrm{~kg}$ (CI:-2.77, -1.20) vs placebo (Figure 2). Results were highly heterogeneous $\left(I^{2}: 86 \%\right)$.

Differences between individual pharmacologic agents and placebo on weight change and weight endpoint are summarized in Figures 2 and 3 and Table 1. Neither weight change $(n=144)$ nor BMI change $(n=21)$ differed between amantadine and placebo (Deberdt et al, 2005; Graham et al, 2005). Weight change with dextroamphetamine did not differ from placebo $(N=1, n=20)$ (Modell and Hussar, 1965). Subjects on D-fenfluramine lost significantly more weight than those on placebo $(N=1, n=16) \quad(\mathrm{WMD}=$ $-2.60 \mathrm{~kg}, \mathrm{CI}:-5.14,-0.06$ ) (Goodall et al, 1988). Famotidine did not differ from placebo regarding weight or BMI change, or BMI endpoint $(N=1, n=14)$ (Poyurovsky et al, 2004). Fluoxetine did not differ from placebo regarding weight change, or weight or BMI endpoint $(N=2, n=60)$ (Bustillo et al, 2003; Poyurovsky et al, 2002). Fluvoxamine and placebo did not differ regarding weight or BMI endpoint $(N=2, n=91)$ (Hinze-Selch et al, 2000; Lu et al, 2004). Across seven studies $(n=334)$, subjects on metformin had 


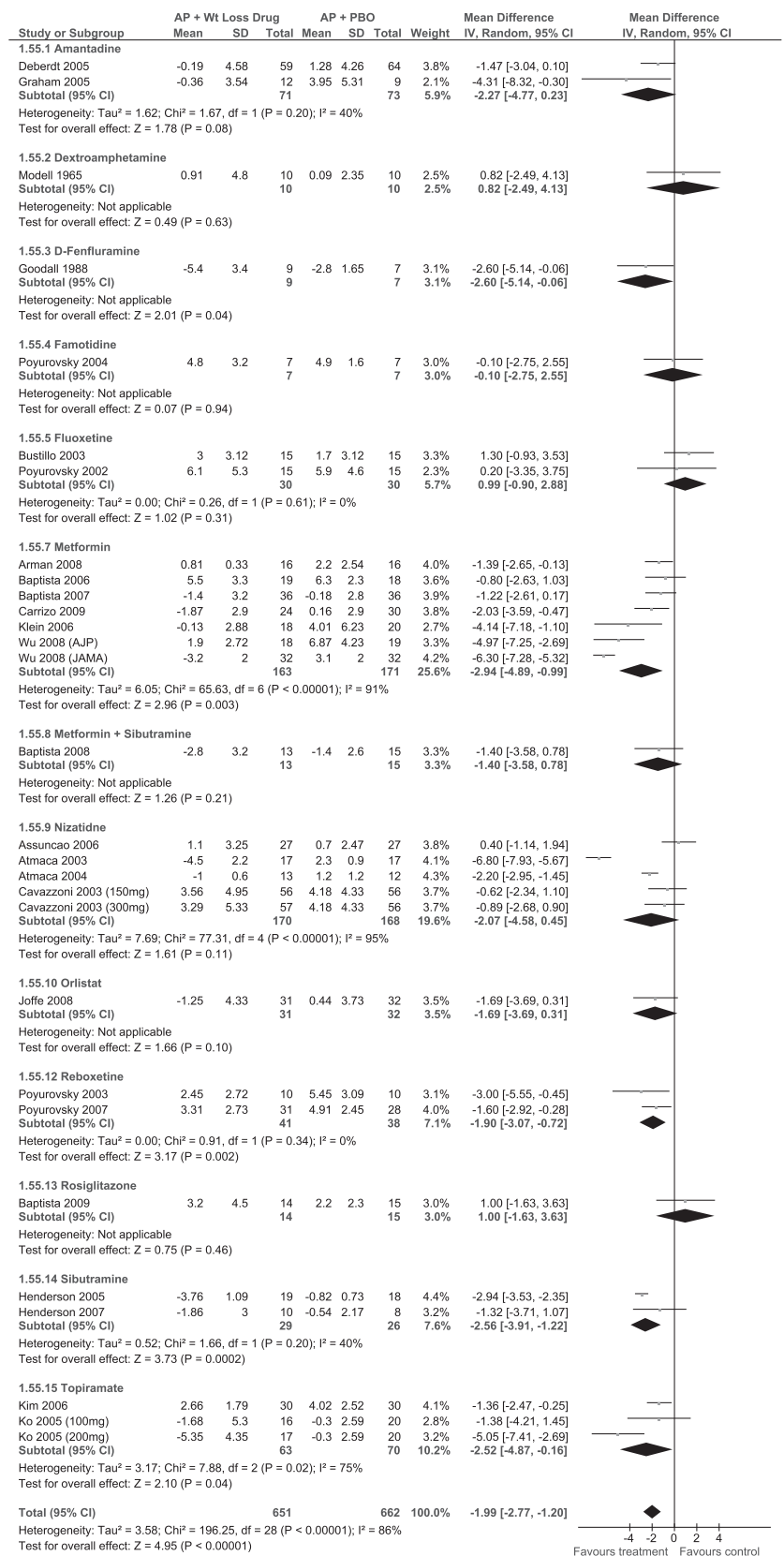

Figure 2 Differences in weight change: forest plot comparing the summarized results and effect sizes (with $95 \% \mathrm{Cls}$ ) for patients on a weight loss medication and those on placebo.

significantly reduced weight compared with placebo $(\mathrm{WMD}=$ $-2.94 \mathrm{~kg}, \mathrm{CI}:-4.89,-0.99$ ) (Arman et al, 2008; Baptista et al, 2006, 2007; Carrizo et al, 2009; Klein et al, 2006; Wu et al, $2008 \mathrm{a}, \mathrm{b})$. Weight endpoint values in four studies $(n=205)$ were also significantly lower in the treatment group (WMD: $-3.37 \mathrm{~kg}, \mathrm{CI}:-6.60,-0.14)$. In addition, subjects on metformin experienced a significant decrease in BMI $(n=265$; $\left.\mathrm{WMD}=-1.36 \mathrm{~kg} / \mathrm{m}^{2}, \mathrm{CI}:-2.20,-0.51\right)$, and in BMI endpoint values compared with placebo $(n=205, \mathrm{WMD}=-1.60 \mathrm{~kg} /$ $\left.\mathrm{m}^{2}, \mathrm{CI}:-2.33,-0.86\right)$.

Overall, nizatidine (Assuncao et al, 2006; Atmaca et al, 2003, 2004; Cavazzoni et al, 2003) did not differ from placebo regarding weight change $(N=4, n=338)$, weight endpoint values $(N=3, n=113)$, and BMI endpoint values
$(N=2, n=59)$. In contrast, two studies $(n=59)$ (Atmaca et al, 2003, 2004) indicated that nizatidine had a significant decrease in BMI compared with placebo (WMD $=-1.98$ $\mathrm{kg} / \mathrm{m}^{2}$, CI: $\left.-3.74,-0.21\right)$. Orlistat did not differ from placebo regarding weight change $(N=1, n=63)$, although a significant difference was found in men (Joffe et al, 2008). Endpoint weight was significantly higher with phenylpropanolamine than with placebo $(N=1, \quad n=16$; $\mathrm{WMD}=4.99 \mathrm{~kg}, \mathrm{CI}: 2.05,7.93$ ) (Borovicka et al, 2002). Compared with placebo, reboxetine (Poyurovsky et al, 2003, 2007) was associated with a significant decrease in weight $(N=2, n=79 ; \mathrm{WMD}=-1.90 \mathrm{~kg}, \mathrm{CI}:-3.07,-0.72)$ and BMI $\left(\mathrm{WMD}=-0.68 \mathrm{~kg} / \mathrm{m}^{2}, \mathrm{CI}:-1.08,-0.28\right)$. However, reboxetine and placebo did not differ on endpoint weight or BMI values. Rosiglitazone and placebo did not differ regarding change or endpoint values in weight or BMI $(N=2, n=47)$ (Baptista et al, 2009; Henderson et al, 2009). Sibutramine was associated with a significant weight reduction compared with placebo $(N=2, n=55$; WMD = $-2.56 \mathrm{~kg}, \mathrm{CI}:-3.91,-1.22$ ) (Henderson et al, 2005, 2007). In addition, the sibutramine group had a significantly lower endpoint weight $(N=1, n=37$; WMD $=-16.96 \mathrm{~kg}$, CI:-27.01, -6.91). Although there was no difference in BMI change between sibutramine $(n=10)$ and placebo $(n=8)$, sibutramine-treated patients $(n=19)$ had a significantly lower BMI than placebo $\left(n=18 ; \mathrm{WMD}=-9.0 \mathrm{~kg} / \mathrm{m}^{2}\right.$, CI:-13.51, -4.49). Topiramate was associated with a significant decrease in weight compared with placebo $(N=2, n=133$; $\mathrm{WMD}=-2.52 \mathrm{~kg}, \mathrm{CI}:-4.87,-0.16)(\mathrm{Kim}$ et al, 2006; Ko et al, 2005). However, topiramate and placebo did not differ regarding BMI change $(n=73)$ and endpoint weight $(n=43)$. In the only trial investigating a combination treatment strategy $(n=28)$, metformin + sibutramine did not differ from placebo regarding change in or endpoint of weight or BMI (Baptista et al, 2008b).

\section{Secondary Outcomes}

Waist circumference and weight gain $\geqslant 7 \%$. Waist circumference (Table 1, Supplementary Figures 1-3) decreased significantly with metformin compared with placebo $\quad(N=5, \quad n=265 ; \quad \mathrm{WMD}=-2.26 \mathrm{~cm}, \mathrm{CI}:-3.99$, $-0.52)$. Significantly less patients gained $\geqslant 7 \%$ of weight with metformin $(N=2, n=69$, RR: 0.24 (CI: $0.09,0.62)$, $p=0.003$, NNT: 3 (CI: $2-6), p<0.0001)$, reboxetine $(N=2$, $n=79$, RR: 0.37 (CI: $0.19,0.75$ ), $p=0.006$, NNT: 3 (CI: $2-8$ ), $p=0.001)$, and fluvoxamine $(N=1, n=68$, RR: 0.27 (CI: $0.08,0.89$ ), $p=0.03$, NNT: 5 (CI: 3-20), $p=0.01$ ) compared with placebo (Table 1, Supplementary Figure 1). Results were nonsignificant for amantadine, famotidine, and fluoxetine.

Carbohydrate metabolism. Compared with placebo, fasting glucose level changes were nonsignificant with metformin, sibutramine, metformin + sibutramine, or rosiglitazone. However, compared with placebo, insulin decreased significantly more with metformin $(N=4, n=220)$ (WMD = $-7.22 \mathrm{uIU} / \mathrm{ml}$; CI: $-12.55,-1.89, p=0.008)$ and rosiglitazone $(N=1, n=29) \quad(\mathrm{WMD}=-13.40 \mathrm{uIU} / \mathrm{ml} ; \mathrm{CI}:-25.47$, $-1.33, p=0.03)$. Drug-placebo differences for insulin endpoints were not different for metformin, metformin + 


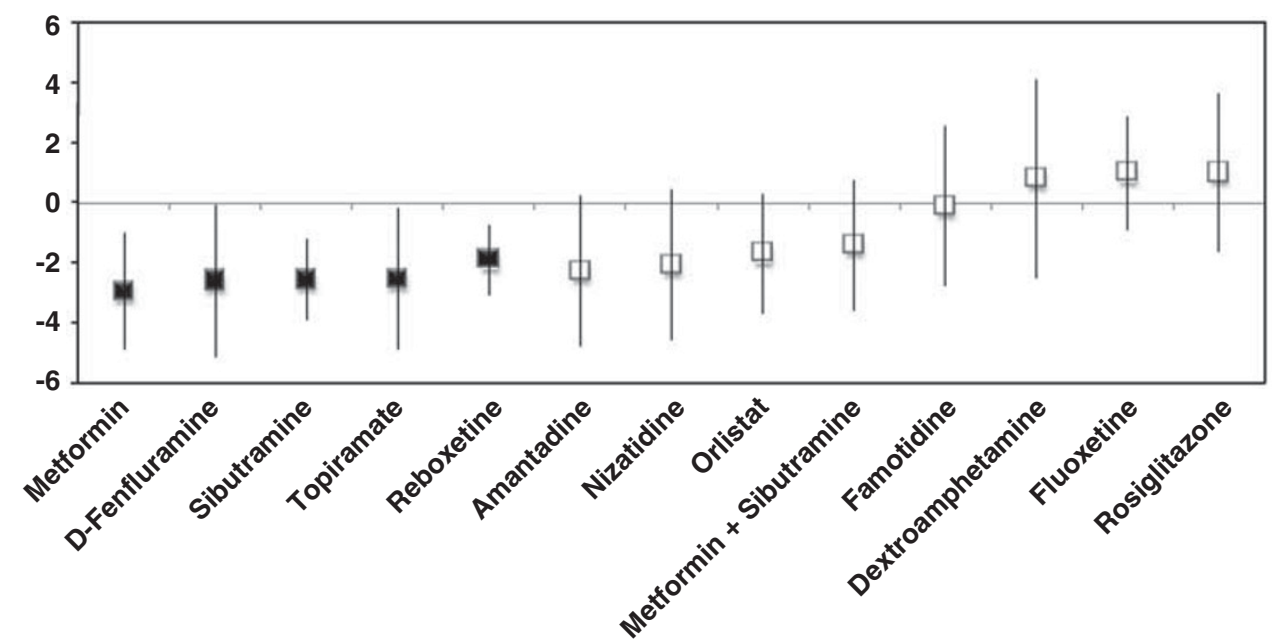

Figure 3 WMD with 95\% confidence interval of weight change in kilograms between pharmacologic treatment and placebo. Shaded boxes indicate agents that separated from placebo.

sibutramine, and rosiglitazone. Although not significant for metformin, rosiglitazone lowered insulin resistance when assessed using the Homeostatic Model Assessment (HOMA) (insulin $\mathrm{uU} / \mathrm{l} \times$ glucose $\mathrm{mmol} / \mathrm{l} / 405$ ) (Matthews et al, 1985) significantly more than placebo $(N=1, n=29$, $\mathrm{WMD}=-2.80$; CI: $-5.19,-0.41, p=0.02)$, yet the opposite was true for metformin + sibutramine $(N=1, n=28$, WMD: +1.10 ; CI: $0.04,2.16, p=0.04$ ).

Blood lipids. There were no significant differences between treatment and placebo regarding changes in total and HDL cholesterol with metformin, sibutramine, metformin + sibutramine, or rosiglitazone. However, triglyceride levels decreased significantly more with metformin + sibutramine than placebo $(N=1, n=28 ; \mathrm{WMD}=-36.8 \mathrm{mg}$ per $100 \mathrm{ml}$, CI:-63.94, $-9.66, p=0.008)$ and triglyceride endpoint levels were lower $(\mathrm{WMD}=-38.6 \mathrm{mg}$ per $100 \mathrm{ml}$, CI:-76.24, $-0.96, p=0.03$ ) (Table 1). Compared with placebo, triglyceride endpoint levels were also significantly lower with metformin $(N=2, n=109$; $\mathrm{WMD}=-28.07 \mathrm{mg}$ per $100 \mathrm{ml}, \mathrm{CI}:-53.22,-2.92, p=0.04)$ and fluvoxamine $(N=1, n=68, \mathrm{WMD}=-22.70 \mathrm{mg}$ per $100 \mathrm{ml}, \mathrm{CI}:-44.59$, $-0.81, p=0.04)$ (Table 1).

There were no treatment-placebo differences regarding LDL-cholesterol change with metformin, sibutramine, and metformin + sibutramine. In contrast, rosiglitazone was associated with a significantly greater increase in LDLcholesterol compared with placebo $(n=29$; WMD: $18.20 \mathrm{mg}$ per $100 \mathrm{ml}, \mathrm{CI}: 2.91,33.48, p=0.02)$. LDL-cholesterol endpoint values were only significantly lower with sibutramine $(n=19)$ compared with placebo $(n=18$; WMD: $-33.80 \mathrm{mg}$ per $100 \mathrm{ml}$, CI: $-60.41,-7.19, p=0.01)$.

Psychiatric symptoms. There were no significant drugplacebo differences regarding changes in any of the reported psychiatric symptoms from baseline to end of study with any treatment (Supplementary Figure 2). However, change in psychiatric symptoms were only reported inconsistently, that is, 6 out of $32(18.8 \%)$ trials reporting change scores and 11 out of $32(34.4 \%)$ trials reporting on endpoint scores on the Brief Psychiatric Rating Scale or change scores on the Positive and Negative Symptom Scale.
Adverse events. There were no significant differences between any treatment and placebo groups for any reported adverse effect (data not shown), but adverse effects were not systematically and comprehensively reported. Nausea, which could be associated with weight loss, was not more frequent compared with placebo with niztidine $(N=1$, $n=225, p=0.91)$, fluvoxamine $(N=1, n=68, p=0.29)$, metformin $(N=2, n=101, p=0.54)$, sibutramine $(N=1$, $n=36, p=0.35)$, and topiramate $(N=1, n=74, p=0.46)$, without heterogeneity across studies (metformin) or doses (nizatidine and topiramate).

\section{Dropout Because of Any Cause, Inefficacy, or Intolerability}

Altogether, pharmacologic interventions and placebo did not differ regarding all-cause discontinuation (RR: 1.03 (CI: $0.85,1.25), p=0.85, I^{2}: 0 \%$ ) (see online Supplementary Figure 6), inefficacy (RR: 1.17 (CI: $0.69,1.99$ ), $p=0.56$, $I^{2}: 0 \%$ ) or intolerability (RR: 1.66 (CI: $0.75,3.66$ ), $p=0.21$, $\left.I^{2}: 0 \%\right)$ (Table 1, Supplementary Figure 3). This also applied to each of the individual medications.

\section{Sensitivity Analyses}

Prevention vs intervention trials. Results of the four sensitivity analyses of potential moderators are summarized in Table 2 and Supplementary Figures 4 and 5. Few individual drug-placebo differences emerged, including significantly greater weight loss with metformin in chronically treated patients; with reboxetine in prevention trials, in studies lasting $<12$ weeks, and for both inpatients and first break patients; and with sibutramine in intervention trials, in studies lasting $\geqslant 12$ weeks, as well as for both outpatients and chronically treated patients. A majority of the results remained significantly heterogeneous if two or more studies provided data.

Publication bias. A funnel plot of standard error $v s$ mean difference showed little evidence of asymmetry to suggest publication bias. All studies fit in a relatively wide funnel with smaller studies showing a symmetrical and 


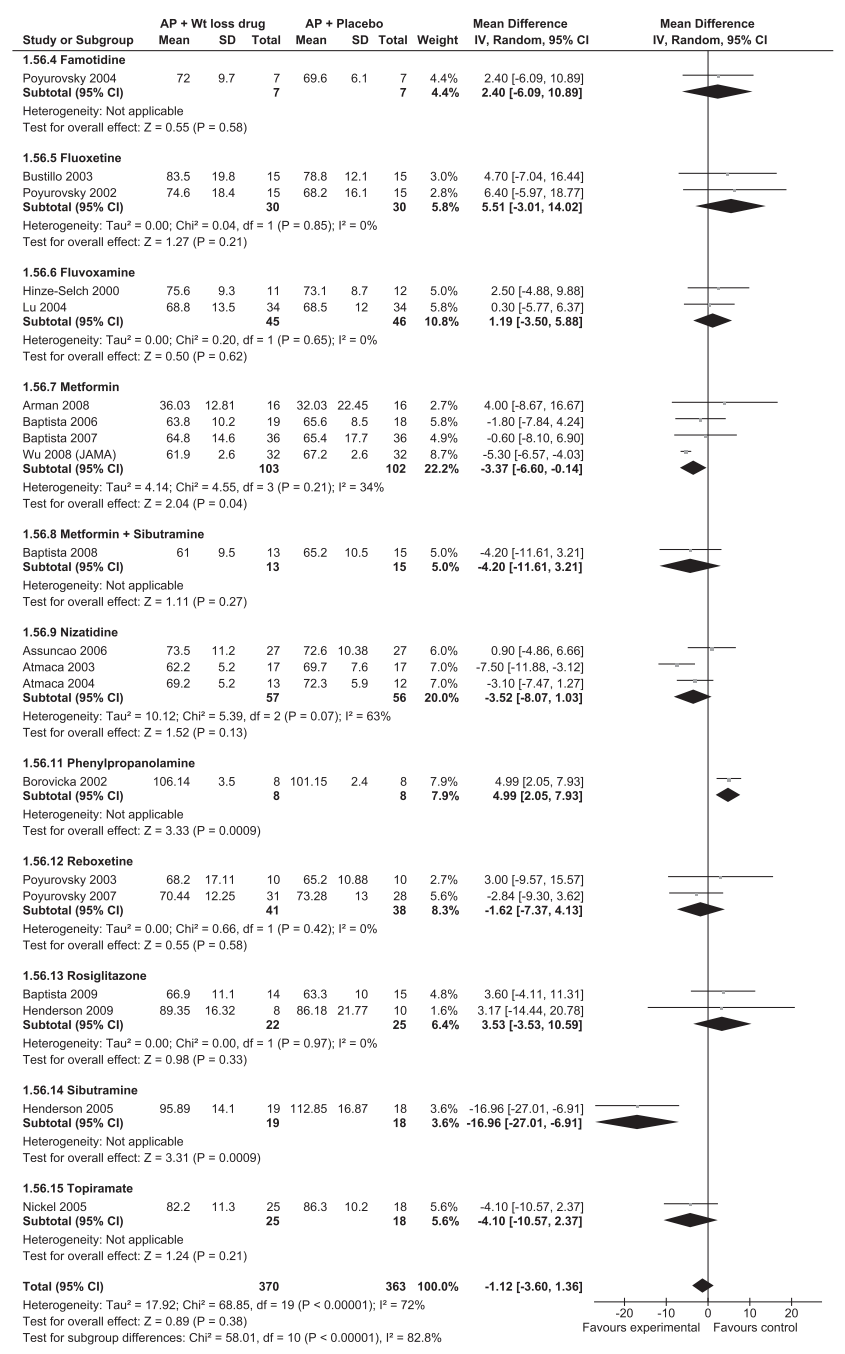

Figure 4 Differences in endpoint weight: forest plot comparing the summarized results and effect sizes (with $95 \% \mathrm{Cls}$ ) for patients on a weight loss medication and those on placebo.

broader range of results than larger studies (Supplemental Figure 6).

\section{DISCUSSION}

For this meta-analysis of pharmacologic interventions to attenuate antipsychotic-associated weight gain, we examined 32 placebo-controlled trials including 1482 subjects that tested 15 different interventions. Data were most consistently available for weight change, showing that, overall, pharmacologic interventions were associated with a weight change of $-1.99 \mathrm{~kg}(\mathrm{CI}:-2.77,-1.20)$ vs placebo over a mean of 13 weeks. However, results were highly heterogeneous, suggesting significant differences across studies and individual agents. Metformin, having the largest database ( $25 \%$ of all patients with weight data), was most superior to placebo $(-2.94 \mathrm{~kg})$, yet results remained heterogeneous even in sensitivity analyses. Additional agents that were superior to placebo included fenfluramine $(-2.60 \mathrm{~kg})$, sibutramine $(-2.56 \mathrm{~kg})$, topiramate $(-2.52 \mathrm{~kg})$, and reboxetine $(-1.90 \mathrm{~kg})$. The nine remaining agents were not superior to placebo in attenuating weight gain, and one (fluvoxamine) did not have data for the primary outcome. In addition, metformin and rosiglitazone showed significant benefits for secondary outcomes, such as waist circumference, blood glucose, and insulin levels. There were no significant individual treatment-placebo differences regarding psychiatric psychopathology and premature dropouts. Regarding prevention of $\geqslant 7 \%$ weight gain, metformin and reboxetine had low and clinically relevant NNTs of 2.5 and 3.0, respectively, with NNTs $<10$ being considered clinically meaningful (Citrome, 2008). Moreover, when reported, nausea, which could lead to weight decrease, occurred as frequently as with placebo for famotidine, fluvoxamine, metformin, sibutramine, and topiramate.

Sensitivity analyses revealed that metformin, given as an intervention after weight gain had occurred, yielded significantly greater weight loss than placebo, whereas preventive treatment started concomitantly with antipsychotic initiation did not separate from placebo. However, results for the intervention trials remained highly heterogeneous. The reduced weight loss effect in the prevention group could be due to the fact that intervention trials are enriched for patients sensitive to weight gain. In addition, in prevention trials, the early orexigenic antipsychotic effect may override the weight loss intervention at this generally more pronounced phase of weight gain (Alvarez-Jimenez et al, 2008). The latter view is supported by data on absolute weight changes within group rather than relative weight differences between treatment and placebo. All nine prevention arms showed absolute weight gain compared with baseline in the treatment group, whereas 15 of the 20 intervention arms showed weight loss compared with baseline when given after weight gain had occurred.

Results remained heterogeneous in sensitivity analyses of youth or first episode patients $v s$ chronically treated patients, likely reflecting the diversity of agents studied. However, younger, less chronic patients did somewhat better. This effect was largest with metformin in which individuals in early treatment lost three times the weight compared with older, more chronic patients. By contrast, inpatient or outpatient status and study duration had a negligible overall effect on weight loss efficacy or heterogeneity of the results, but larger studies are needed to more comprehensively assess these and additional moderator variables.

Although the observed weight loss and more isolated metabolic improvements with some agents reached statistical significance, the magnitude of these changes was modest. Even in studies with the most pronounced effects, subjects only lost part of the weight that they likely accrued during antipsychotic treatment. For example, although patients on amantadine lost $-6.80 \mathrm{~kg}$ (CI:-5.67, -7.93) more than placebo (Atmaca et al, 2003), the absolute weight loss in the treatment group was $-4.6 \pm 2.2 \mathrm{~kg}$, which was less than the amount that many individuals had gained in the 3 months before study entry (ie, $2.6-10.8 \mathrm{~kg}$ ). Similarly, although patients on metformin lost $-6.3 \mathrm{~kg}$ (CI:-5.32, -7.28) more than placebo (Wu et al, 2008b), the absolute weight loss of $-3.2 \pm 2 \mathrm{~kg}$ was clearly less than the minimum of $10 \%$ weight gain that was required for study inclusion. Furthermore, in the few medium-term studies, the weight loss signal did not seem to be amplified 
Table I Significant Differences Between Placebo and Intervention Group Regarding Secondary Outcome Measures

\begin{tabular}{|c|c|c|c|c|c|c|c|c|c|c|c|c|c|c|c|}
\hline & $\underset{(n)}{\text { Amantadine }}$ & $\begin{array}{l}\text { Dextro- } \\
\text { Amphet- } \\
\text { amine (n) }\end{array}$ & $\begin{array}{l}\text { D-Fenflur- } \\
\text { amine }(n)\end{array}$ & $\begin{array}{l}\text { Famotidine } \\
(n)\end{array}$ & $\begin{array}{l}\text { Fluoxetine } \\
\text { (n) }\end{array}$ & $\begin{array}{l}\text { Fluvoxamine } \\
\qquad(n)\end{array}$ & $\begin{array}{l}\text { Metformin } \\
\text { (n) }\end{array}$ & $\begin{array}{l}\text { Nizatidine } \\
\text { (n) }\end{array}$ & $\begin{array}{l}\text { Orlistat } \\
\qquad(n)\end{array}$ & $\begin{array}{l}\text { Phenyl- } \\
\text { propanol- } \\
\text { amine (n) }\end{array}$ & $\begin{array}{l}\text { Reboxetine } \\
(n)\end{array}$ & $\begin{array}{l}\text { Rosiglitazone } \\
(n)\end{array}$ & $\begin{array}{l}\text { Sibutramine } \\
(n)\end{array}$ & $\underset{(n)}{\text { Topiramate }}$ & $\begin{array}{c}\text { Metformin + } \\
\text { sibutramine (n) }\end{array}$ \\
\hline \multicolumn{16}{|c|}{ Risk ratio $\pm 95 \% \mathrm{Cl}$} \\
\hline$\geqslant 7 \%$ weight gain & NS & - & - & NS & NS & $\begin{array}{c}0.27 \\
(0.08,0.89) \\
(1)\end{array}$ & $\begin{array}{c}0.24 \\
(0.09,0.62) \\
(2)\end{array}$ & - & - & - & $\begin{array}{c}0.37 \\
(0.19,0.75)(2)\end{array}$ & - & - & - & - \\
\hline Dropouts: any cause & NS & - & NS & NS & NS & NS & NS & NS & NS & - & NS & - & NS & NS & NS \\
\hline Dropouts: intolerability & NS & - & NS & NS & - & NS & NS & NS & NS & - & NS & - & NS & NS & NS \\
\hline Dropouts: inefficacy & NS & - & NS & NS & NS & NS & NS & - & NS & - & NS & - & NS & NS & NS \\
\hline \multicolumn{16}{|c|}{ Weighted mean difference $\pm 95 \% \mathrm{Cl}$} \\
\hline Waist circumference change & - & - & - & - & - & - & $\begin{array}{c}-2.26 \\
(-3.99,-0.52) \\
(5)\end{array}$ & - & - & - & - & NS & NS & - & NS \\
\hline Glucose change & - & - & - & - & - & - & NS & - & NS & - & - & NS & NS & - & NS \\
\hline Glucose endpoint & - & - & - & - & - & $\begin{array}{c}-3.30 \\
(-6.32,-0.28) \\
\text { (I) }\end{array}$ & $\begin{array}{c}-6.38 \\
(-10.74,-2.03) \\
(3)\end{array}$ & - & - & - & - & NS & NS & - & NS \\
\hline Insulin change & - & - & - & - & - & - & $\begin{array}{c}-7.22 \\
(-12.55,-1.89) \\
(4)\end{array}$ & - & - & - & - & $\begin{array}{c}-13.40 \\
(-25.47,-1.33)(1)\end{array}$ & - & - & NS \\
\hline Insulin endpoint & - & - & - & - & - & - & NS & - & - & - & - & NS & - & - & NS \\
\hline Leptin change & - & - & - & - & - & - & NS & NS & - & - & - & - & - & - & NS \\
\hline Leptin endpoint & - & - & - & - & - & NS & - & - & - & - & - & - & - & - & - \\
\hline HOMA-IR change & - & - & - & - & - & - & NS & - & - & - & - & $\begin{array}{c}-2.80 \\
(-5.19,-0.41)(1)\end{array}$ & - & - & $\begin{array}{c}1.10 \\
(0.04,2.16)(1)\end{array}$ \\
\hline HOMA-IR endpoint & - & - & - & - & - & - & NS & - & - & - & - & NS & - & - & NS \\
\hline Total cholesterol change & - & - & - & - & - & - & NS & - & NS & - & - & NS & NS & - & NS \\
\hline Total cholesterol endpoint & - & - & - & - & - & NS & NS & NS & - & - & - & $\begin{array}{c}-21.30 \\
(-39.01,-3.59)(1)\end{array}$ & NS & - & NS \\
\hline HDL-cholesterol change & - & - & - & - & - & - & NS & - & NS & - & - & NS & NS & - & NS \\
\hline HDL-cholesterol endpoint & - & - & - & - & - & - & NS & NS & - & - & - & NS & NS & - & NS \\
\hline LDL-cholesterol change & - & - & - & - & - & - & NS & - & NS & - & - & $\begin{array}{c}18.20 \\
(2.91,33.49)(1)\end{array}$ & NS & - & NS \\
\hline LDL-cholesterol endpoint & - & - & - & - & - & - & NS & NS & - & - & - & $\begin{array}{c}-16.00 \\
(-30.85,-1.15) \\
(1)\end{array}$ & $\begin{array}{c}-33.80 \\
(-60.44,-7.19)(1)\end{array}$ & - & NS \\
\hline Triglyceride change & - & - & - & - & - & - & NS & - & - & - & - & NS & NS & - & $\begin{array}{c}-36.80 \\
(-63.94,-9.66)(1)\end{array}$ \\
\hline Triglyceride endpoint & - & - & - & - & - & $\begin{array}{c}-22.70 \\
(-44.59,-0.81) \\
\text { (I) }\end{array}$ & $\begin{array}{c}-28.07 \\
(-53.22,-2.92) \\
(2)\end{array}$ & NS & - & - & - & NS & NS & - & $\begin{array}{c}-38.60 \\
(-76.24,-0.96)(1)\end{array}$ \\
\hline BPRS/PANSS total score change & - & - & - & - & - & - & NS & NS & - & - & - & NS & NS & - & NS \\
\hline $\begin{array}{l}\text { BPRS/PANSS total score } \\
\text { endpoint }\end{array}$ & NS & - & - & - & - & - & NS & NS & - & NS & - & NS & NS & - & NS \\
\hline
\end{tabular}

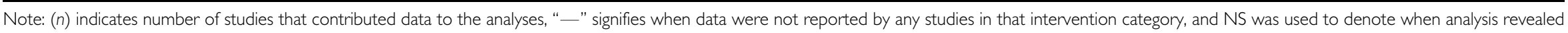
nonsignificant results. 
Table 2 Significant Differences in Weight Change (kg) Between Placebo and Treatment Group with Corresponding Heterogeneity Values Where Applicable in Four Sensitivity Analyses

\begin{tabular}{|c|c|c|c|c|c|c|c|c|c|}
\hline & \multicolumn{2}{|c|}{$\begin{array}{l}\text { Prevention vs } \\
\text { intervention }\end{array}$} & \multicolumn{2}{|c|}{$\begin{array}{c}\text { Study } \\
\text { duration }\end{array}$} & \multicolumn{3}{|c|}{$\begin{array}{l}\text { Hospitalization } \\
\text { status }\end{array}$} & \multicolumn{2}{|c|}{$\begin{array}{l}\text { Lifetime antipsychotic } \\
\text { treatment duration }\end{array}$} \\
\hline & $\begin{array}{l}\text { Intervention } \\
\left(I^{2}=89 \%\right)\end{array}$ & $\begin{array}{l}\text { Prevention } \\
\left(I^{2}=44 \%\right)\end{array}$ & $\begin{array}{l}\text { Short term: } \\
<12 \text { weeks } \\
\left(I^{2}=91 \%\right)\end{array}$ & $\begin{array}{l}\text { Medium term: } \\
\begin{array}{l}\geqslant \mid 2 \text { weeks } \\
\left(I^{2}=84 \%\right)\end{array}\end{array}$ & $\begin{array}{l}\text { Inpatients } \\
\left(I^{2}=59 \%\right)\end{array}$ & $\begin{array}{l}\text { Outpatients } \\
\left(I^{2}=91 \%\right)\end{array}$ & $\begin{array}{l}\text { Mixed: inpatients } \\
\text { and outpatients } \\
\qquad\left(I^{2}=91 \%\right)\end{array}$ & $\begin{array}{l}\text { Youth and } \\
\text { first-break } \\
\left(I^{2}=90 \%\right)\end{array}$ & $\begin{array}{l}\text { Chronically } \\
\text { ill }\left(I^{2}=83 \%\right)\end{array}$ \\
\hline Amantadine & NS (2) & - & - & NS (2) & - & $\begin{array}{c}-4.31 \\
(-8.32,-0.30)(1)\end{array}$ & NS (I) & - & NS (2) \\
\hline Dextroamphetamine & NS & - & NS (I) & - & $N S(I)$ & - & - & - & NS (I) \\
\hline D-Fenfluramine & $\begin{array}{c}-2.60 \\
(-5.14,-0.06)(1)\end{array}$ & - & - & $\begin{array}{c}-2.60 \\
(-5.14,-0.06)(1)\end{array}$ & - & $\begin{array}{c}-2.60 \\
(-5.14,-0.06)(1)\end{array}$ & - & - & $\begin{array}{c}-2.60 \\
(-5.14,-0.06)(1)\end{array}$ \\
\hline Famotidine & - & NS (I) & NS (I) & - & NS (I) & - & - & NS $(I)$ & - \\
\hline Fluoxetine & NS (I) & NS (I) & NS (I) & NS (I) & NS (I) & NS (I) & - & NS (2) & - \\
\hline Fluvoxamine & - & - & - & - & - & - & - & - & - \\
\hline Metformin & $\begin{array}{c}-2.99 \\
(-5.40,-0.58)(5) \\
I^{2}=93 \%\end{array}$ & NS (2) & - & $\begin{array}{c}-2.94 \\
(-4.89,-0.99)(7) \\
I^{2}=91 \%\end{array}$ & $\begin{array}{c}-2.59 \\
(-4.48,-0.69)(4) \\
I^{2}=73 \%\end{array}$ & $\begin{array}{c}-4.21 \\
(-8.39,-0.03)(2), \\
I^{2}=95 \%\end{array}$ & NS (I) & $\begin{array}{c}-4.19 \\
(-7.02,-1.36)(4) \\
I^{2}=92 \%\end{array}$ & $\begin{array}{c}-1.39 \\
(-2.29,-0.49)(3), \\
P^{2}=0 \%\end{array}$ \\
\hline Nizatidine & NS (3) & NS (I) & NS (2) & NS (2) & - & NS (I) & NS (3) & - & NS (4) \\
\hline Orlistat & NS (I) & - & - & NS (I) & - & - & NS (I) & - & NS (I) \\
\hline Phenylpropanolamine & - & - & - & - & - & - & - & - & - \\
\hline Reboxetine & - & $\begin{array}{c}-1.90 \\
(-3.07,-0.72)(2), \\
R^{2}=0 \%\end{array}$ & $\begin{array}{c}-1.90 \\
(-3.07,-0.72)(2), \\
P^{2}=0 \%\end{array}$ & - & $\begin{array}{c}-1.90 \\
(-3.07,-0.72)(2) \\
P^{2}=0 \%\end{array}$ & - & - & $\begin{array}{c}-1.90 \\
(-3.07,-0.72)(2) \\
R^{2}=0 \%\end{array}$ & - \\
\hline Rosiglitazone & NS (I) & - & - & NS (I) & NS (I) & - & - & - & NS (I) \\
\hline Sibutramine & $\begin{array}{c}-2.56 \\
(-3.91,-1.22)(2) \\
P^{2}=40 \%\end{array}$ & - & - & $\begin{array}{c}-2.56 \\
(-3.91,-1.22)(2) \\
I^{2}=40 \%\end{array}$ & - & $\begin{array}{c}-2.56 \\
(-3.91,-1.22)(2) \\
P^{2}=40 \%\end{array}$ & - & - & $\begin{array}{c}-2.56 \\
(-3.19,-1.22)(2) \\
P^{2}=40 \%\end{array}$ \\
\hline Topiramate & NS (I) & $\begin{array}{c}-1.36 \\
(-2.47,-0.25)(1)\end{array}$ & - & $\begin{array}{c}-2.52 \\
(-4.87,-0.16)(2) \\
I^{2}=75 \%\end{array}$ & NS (I) & $\begin{array}{c}-1.36 \\
(-2.47,-0.25)(1)\end{array}$ & - & - & $\begin{array}{c}-2.52 \\
(-4.87,-0.16)(2) \\
P^{2}=75 \%\end{array}$ \\
\hline Metformin+sibutramine & NS (I) & - & - & NS (I) & NS (I) & - & - & - & NS (I) \\
\hline
\end{tabular}


compared with shorter-term trials. Thus, although longerterm studies are needed, it seems that for many individuals the adjunctive pharmacological agents studied are unlikely to return their weight to baseline.

Assuming that comparable populations were studied, and comparing our pooled results across all pharmacologic treatments (ie, $-1.99 \mathrm{~kg}(\mathrm{CI}:-1.20,-2.77)$ ) with the pooled weight loss of $-2.56 \mathrm{~kg}(\mathrm{CI}:-1.92,-3.20)$ across all nonpharmacologic interventions from a recent meta-analysis of non-pharmacological interventions (Alvarez-Jimenez et al, 2008), one could draw the conclusion that nonpharmacologic interventions are more effective. However, in the only randomized study in our meta-analysis in which these modalities were compared directly (Wu et al, 2008b), the pharmacological intervention-metforminperformed significantly better than the non-pharmacological treatment $(-3.2 \mathrm{~kg}(\mathrm{CI}:-2.5,-3.9))$ vs $-1.4 \mathrm{~kg}(\mathrm{CI}:-0.7$, $-2.0 ; p<0.05)$. It is noteworthy that the most efficacious treatment in that study was the combined metformin and behavioral intervention $(-4.7 \mathrm{~kg}$ (CI:-3.4, -5.7$))$. Thus, it appears that overall results across non-pharmacologic treatments are more consistent, whereas tested pharmacologic treatments included some that are clearly noneffective.

Although metformin outperformed other agents that have been studied against placebo, the current evidence is too limited to support its regular clinical use as an adjunctive medication. Data regarding the metformin related, rare, but potentially fatal side effect of lactic acidosis, particularly in elderly and those with compromised renal function (Chang et al, 2002), and its new-found association with the accumulation of beta-amyloid, a factor in the pathogenesis of Alzheimer's disease (Chen et al, 2009), alter the riskbenefit ratio in the elderly. However, the results do support further investigation of the risks and benefits of metformin in large, well-controlled trials in comparison with lower risk interventions such as switching to an antipsychotic medication with a lesser cardio metabolic burden, healthy lifestyle interventions and nutritional counseling.

The main limitation of this meta-analysis is the relative paucity of randomized controlled trials. As a result, there are too few studies for a number of medications, including orlistat and topiramate. Furthermore, there are no head-tohead studies of pharmacologic interventions, and only one study compared pharmacologic, nonpharmacologic, and combined pharmacologic plus non-pharmacologic interventions against placebo (Wu et al, 2008b). Another related limitation is the heterogeneity of the results across individual studies that did not seem to be related to treatment setting, treatment duration, illness chronicity, and timing of the intervention, yet, our attempt to examine this heterogeneity through sensitivity analyses was hindered by a lack of statistical power. Thus, the variability of the effects may be explained by biological and/or environmental differences in patient cohorts and treatment environments, including studies that were performed in China and Venezuela, societies with different populations, weight norms and diets than in North America and Europe. Moreover, the heterogeneity of the results could also be due to different weight loss mechanisms of individual augmenting agents, and the strength of this effect could even differ based on which antipsychotic caused or maintains the weight gain and/or metabolic changes. It is noteworthy that we were not able to substantiate that metformin or other medications, for which information was available, were associated with greater rates of nausea that could be related to the observed weight loss. In spite of these limitations, this is the largest meta-analysis of pharmacologic weight loss interventions for antipsychotic weight gain. Compared with the previous meta-analysis on this topic (Faulkner et al, 2007b), we included an additional 10 trials and 714 patients, allowing a more in-depth assessment of some individual agents and the added exploration of moderating variables.

The heterogeneous and relatively modest results of pharmacologic interventions for antipsychotic weight gain indicate the urgent need for more research in this area of high public health importance. Future research should consist of large studies that assess a wide array of body composition and metabolic parameters, document previous treatment history and weight change carefully, and focus on moderators and mediators of the response, ideally including a pharmacogenetic component (Correll and Malhotra, 2004). Studies are also needed that document the time course and sustainability of weight loss over longer periods of time. Moreover, studies are needed in antipsychoticnaïve patients and in children and adolescents, who are at particular risk for weight gain and its long-term consequences (Alvarez-Jimenez et al, 2008; Correll, 2008). Furthermore, studies should be conducted in patients with disorders other than schizophrenia for which antipsychotics are endorsed (Suppes et al, 2005) or prescribed frequently (Olfson et al, 2006). Finally, studies are needed that examine the mechanisms of antipsychotic-induced weight gain and metabolic abnormalities to enable the development and testing of more targeted interventions that are hoped to be associated with greater weight loss efficacy and improved health outcomes in patients requiring antipsychotic treatment.

\section{ACKNOWLEDGEMENTS}

This work was supported in parts by The Zucker Hillside Hospital National Institute of Mental Health (NIMH) Advanced Center for Intervention and Services Research for the Study of Schizophrenia MH 074543-01.

\section{DISCLOSURE}

Dr Maayan has received research support from Eli Lilly and Pfizer. Dr Correll has been a consultant to or has received honoraria from Actelion, AstraZeneca, BristolMyers Squibb, Cephalon, Eli Lilly, GSK, Janssen/J\&J, Lundbeck, Otsuka, Medicure, Pfizer, Schering-Plough, Supernus Takeda, and Vanda. Ms Vakhrusheva has nothing to disclose.

\section{REFERENCES}

Allison DB, Mackell JA, McDonnell DD (2003). The impact of weight gain on quality of life among persons with schizophrenia. Psychiatr Serv 54: 565-567. 
Allison DB, Mentore JL, Heo M, Chandler LP, Cappelleri JC, Infante MC et al (1999). Antipsychotic-induced weight gain: a comprehensive research synthesis. Am J Psychiatry 156: 1686-1696.

Alvarez-Jimenez M, Hetrick SE, Gonzalez-Blanch C, Gleeson JF, McGorry PD (2008). Non-pharmacological management of antipsychotic-induced weight gain: systematic review and meta-analysis of randomised controlled trials. $\mathrm{Br} J$ Psychiatry 193: 101-107.

Arman S, Sadramely MR, Nadi M, Koleini N (2008). A randomized, double-blind, placebo-controlled trial of metformin treatment for weight gain associated with initiation of risperidone in children and adolescents. Saudi Med J 29: 1130-1134.

Assuncao SS, Ruschel SI, Rosa Lde C, Campos JA, Alves MJ, Bracco OL et al (2006). Weight gain management in patients with schizophrenia during treatment with olanzapine in association with nizatidine. Rev Bras Psiquiatr 28: 270-276.

Atmaca M, Kuloglu M, Tezcan E, Ustundag B (2003). Nizatidine treatment and its relationship with leptin levels in patients with olanzapine-induced weight gain. Hum Psychopharmacol 18: 457-461.

Atmaca M, Kuloglu M, Tezcan E, Ustundag B, Kilic N (2004). Nizatidine for the treatment of patients with quetiapine-induced weight gain. Hum Psychopharmacol 19: 37-40.

Baptista T, ElFakih Y, Uzcategui E, Sandia I, Talamo E, Araujo de Baptista E et al (2008a). Pharmacological management of atypical antipsychotic-induced weight gain. CNS Drugs 22: 477-495.

Baptista T, Martinez J, Lacruz A, Rangel N, Beaulieu S, Serrano A et al (2006). Metformin for prevention of weight gain and insulin resistance with olanzapine: a double-blind placebo-controlled trial. Can J Psychiatry 51: 192-196.

Baptista T, Rangel N, El Fakih Y, Uzcategui E, Galeazzi T, Beaulieu S et al (2009). Rosiglitazone in the assistance of metabolic control during olanzapine administration in schizophrenia: a pilot double-blind, placebo-controlled, 12-week trial. Pharmacopsychiatry 42: 14-19.

Baptista T, Rangel N, Fernandez V, Carrizo E, El Fakih Y, Uzcategui $\mathrm{E}$ et al (2007). Metformin as an adjunctive treatment to control body weight and metabolic dysfunction during olanzapine administration: a multicentric, double-blind, placebo-controlled trial. Schizophr Res 93: 99-108.

Baptista T, Uzcategui E, Rangel N, El Fakih Y, Galeazzi T, Beaulieu S et al (2008b). Metformin plus sibutramine for olanzapine-associated weight gain and metabolic dysfunction in schizophrenia: a 12-week double-blind, placebo-controlled pilot study. Psychiatry Res 159: 250-253.

Borovicka MC, Fuller MA, Konicki PE, White JC, Steele VM, Jaskiw GE (2002). Phenylpropanolamine appears not to promote weight loss in patients with schizophrenia who have gained weight during clozapine treatment. J Clin Psychiatry 63: 345-348.

Bustillo JR, Lauriello J, Parker K, Hammond R, Rowland L, Bogenschutz $\mathrm{M}$ et al (2003). Treatment of weight gain with fluoxetine in olanzapine-treated schizophrenic outpatients. Neuropsychopharmacology 28: 527-529.

Carrizo E, Fernandez V, Connell L, Sandia I, Prieto D, Mogollon J et al (2009). Extended release metformin for metabolic control assistance during prolonged clozapine administration: a 14 week, double-blind, parallel group, placebo-controlled study. Schizophr Res 113: 19-26.

Cavazzoni P, Tanaka Y, Roychowdhury SM, Breier A, Allison DB (2003). Nizatidine for prevention of weight gain with olanzapine: a double-blind placebo-controlled trial. Eur Neuropsychopharmacol 13: 81-85.

Chang CT, Chen YC, Fang JT, Huang CC (2002). Metforminassociated lactic acidosis: case reports and literature review. J Nephrol 15: 398-402.

Chen Y, Zhou K, Wang R, Liu Y, Kwak YD, Ma $\mathrm{T}$ et al (2009). Antidiabetic drug metformin (GlucophageR) increases biogenesis of Alzheimer's amyloid peptides via up-regulating BACE1 transcription. Proc Natl Acad Sci USA 106: 3907-3912.

Citrome L (2008). Compelling or irrelevant? Using number needed to treat can help decide. Acta Psychiatr Scand 117: 412-419.

Colton CW, Manderscheid RW (2006). Congruencies in increased mortality rates, years of potential life lost, and causes of death among public mental health clients in eight states. Prev Chronic Dis 3: A42.

Correll CU (2007). Balancing efficacy and safety in treatment with antipsychotics. CNS Spectr 12(10 Suppl 17): 12-20 35.

Correll CU (2008). Antipsychotic use in children and adolescents: minimizing adverse effects to maximize outcomes. J Am Acad Child Adolesc Psychiatry 47: 9-20.

Correll CU, Malhotra AK (2004). Pharmacogenetics of antipsychotic-induced weight gain. Psychopharmacology (Berl) 174: 477-489.

Deberdt W, Winokur A, Cavazzoni PA, Trzaskoma QN, Carlson CD, Bymaster FP et al (2005). Amantadine for weight gain associated with olanzapine treatment. Eur Neuropsychopharmacol 15: 13-21.

Faulkner G, Cohn T, Remington G (2007a). Interventions to reduce weight gain in schizophrenia. Cochrane Database Syst Rev (1) CD005148.

Faulkner G, Cohn T, Remington G (2007b). Interventions to reduce weight gain in schizophrenia. Schizophr Bull 33: 654-656.

Goodall E, Oxtoby C, Richards R, Watkinson G, Brown D, Silverstone $\mathrm{T}$ (1988). A clinical trial of the efficacy and acceptability of $\mathrm{D}$-fenfluramine in the treatment of neuroleptic-induced obesity. Br J Psychiatry 153: 208-213.

Graham KA, Gu H, Lieberman JA, Harp JB, Perkins DO (2005). Double-blind, placebo-controlled investigation of amantadine for weight loss in subjects who gained weight with olanzapine. Am J Psychiatry 162: 1744-1746.

Henderson DC, Copeland PM, Daley TB, Borba CP, Cather C, Nguyen DD et al (2005). A double-blind, placebo-controlled trial of sibutramine for olanzapine-associated weight gain. $A m \mathrm{~J}$ Psychiatry 162: 954-962.

Henderson DC, Fan X, Copeland PM, Borba CP, Daley TB, Nguyen DD et al (2007). A double-blind, placebo-controlled trial of sibutramine for clozapine-associated weight gain. Acta Psychiatr Scand 115: 101-105.

Henderson DC, Fan X, Sharma B, Copeland PM, Borba CP, Boxill R et al (2009). A double-blind, placebo-controlled trial of rosiglitazone for clozapine-induced glucose metabolism impairment in patients with Schizophrenia. Acta Psychiatr Scand 119: 457-465.

Higgins JP, Thompson SG, Deeks JJ, Altman DG (2003). Measuring inconsistency in meta-analyses. BMJ 327: 557-560.

Hinze-Selch D, Deuschle M, Weber B, Heuser I, Pollmacher T (2000). Effect of coadministration of clozapine and fluvoxamine versus clozapine monotherapy on blood cell counts, plasma levels of cytokines and body weight. Psychopharmacology (Berl) 149: 163-169.

Joffe G, Takala P, Tchoukhine E, Hakko H, Raidma M, Putkonen H et al (2008). Orlistat in clozapine- or olanzapine-treated patients with overweight or obesity: a 16-week randomized, double-blind, placebo-controlled trial. J Clin Psychiatry 69: 706-711.

Kim JH, Yim SJ, Nam JH (2006). A 12-week, randomized, openlabel, parallel-group trial of topiramate in limiting weight gain during olanzapine treatment in patients with schizophrenia. Schizophr Res 82: 115-117.

Klein DJ, Cottingham EM, Sorter M, Barton BA, Morrison JA (2006). A randomized, double-blind, placebo-controlled trial of metformin treatment of weight gain associated with initiation of atypical antipsychotic therapy in children and adolescents. $A m \mathrm{~J}$ Psychiatry 163: 2072-2079.

Ko YH, Joe SH, Jung IK, Kim SH (2005). Topiramate as an adjuvant treatment with atypical antipsychotics in schizophrenic 
patients experiencing weight gain. Clin Neuropharmacol 28: $169-175$.

Kroeze WK, Hufeisen SJ, Popadak BA, Renock SM, Steinberg S, Ernsberger P et al (2003). H1-histamine receptor affinity predicts short-term weight gain for typical and atypical antipsychotic drugs. Neuropsychopharmacology 28: 519-526.

Leucht S, Corves C, Arbter D, Engel RR, Li C, Davis JM (2009a). Second-generation versus first-generation antipsychotic drugs for schizophrenia: a meta-analysis. Lancet 373: 31-41.

Leucht S, Komossa K, Rummel-Kluge C, Corves C, Hunger H, Schmid F et al (2009b). A meta-analysis of head-to-head comparisons of second-generation antipsychotics in the treatment of schizophrenia. Am J Psychiatry 166: 152-163.

Lu ML, Lane HY, Lin SK, Chen KP, Chang WH (2004). Adjunctive fluvoxamine inhibits clozapine-related weight gain and metabolic disturbances. J Clin Psychiatry 65: 766-771.

Matthews DR, Hosker JP, Rudenski AS, Naylor BA, Treacher DF, Turner RC (1985). Homeostasis model assessment: insulin resistance and beta-cell function from fasting plasma glucose and insulin concentrations in man. Diabetologia 28: 412-419.

Modell W, Hussar AE (1965). Failure of dextroamphetamine sulfate to influence eating and sleeping patterns in obese schizophrenic patients: clinical and pharmacological significance. JAMA 193: 275-278.

Newcomer JW (2005). Second-generation (atypical) antipsychotics and metabolic effects: a comprehensive literature review. CNS Drugs 19(Suppl 1): 1-93.

Nickel MK, Nickel C, Muehlbacher M, Leiberich PK, Kaplan P, Lahmann C et al (2005). Influence of topiramate on olanzapinerelated adiposity in women: a random, double-blind, placebocontrolled study. J Clin Psychopharmacol 25: 211-217.

Olfson M, Blanco C, Liu L, Moreno C, Laje G (2006). National trends in the outpatient treatment of children and adolescents with antipsychotic drugs. Arch Gen Psychiatry 63: 679-685.

Perkins DO (2002). Predictors of noncompliance in patients with schizophrenia. J Clin Psychiatry 63: 1121-1128.
Poyurovsky M, Fuchs C, Pashinian A, Levi A, Faragian S, Maayan $\mathrm{R}$ et al (2007). Attenuating effect of reboxetine on appetite and weight gain in olanzapine-treated schizophrenia patients: a double-blind placebo-controlled study. Psychopharmacology (Berl) 192: 441-448.

Poyurovsky M, Isaacs I, Fuchs C, Schneidman M, Faragian S, Weizman $\mathrm{R}$ et al (2003). Attenuation of olanzapine-induced weight gain with reboxetine in patients with schizophrenia: a double-blind, placebo-controlled study. Am J Psychiatry 160: 297-302.

Poyurovsky M, Pashinian A, Gil-Ad I, Maayan R, Schneidman M, Fuchs $C$ et al (2002). Olanzapine-induced weight gain in patients with first-episode schizophrenia: a double-blind, placebocontrolled study of fluoxetine addition. Am J Psychiatry 159: 1058-1060.

Poyurovsky M, Tal V, Maayan R, Gil-Ad I, Fuchs C, Weizman A (2004). The effect of famotidine addition on olanzapine-induced weight gain in first-episode schizophrenia patients: a doubleblind placebo-controlled pilot study. Eur Neuropsychopharmacol 14: 332-336.

Suppes T, Kelly DI, Perla JM (2005). Challenges in the management of bipolar depression. J Clin Psychiatry 66(Suppl 5): 11-16.

Templeman LA, Reynolds GP, Arranz B, San L (2005). Polymorphisms of the 5-HT2C receptor and leptin genes are associated with antipsychotic drug-induced weight gain in Caucasian subjects with a first-episode psychosis. Pharmacogenet Genomics 15: 195-200.

Wu RR, Zhao JP, Guo XF, He YQ, Fang MS, Guo WB et al (2008a). Metformin addition attenuates olanzapine-induced weight gain in drug-naive first-episode schizophrenia patients: a double-blind, placebo-controlled study. Am J Psychiatry 165: 352-358.

Wu RR, Zhao JP, Jin H, Shao P, Fang MS, Guo XF et al (2008b). Lifestyle intervention and metformin for treatment of antipsychotic-induced weight gain: a randomized controlled trial. JAMA 299: 185-193.

Supplementary Information accompanies the paper on the Neuropsychopharmacology website (http://www.nature.com/npp) 